\title{
FABULAÇÃO NA GAIOLA, DOBRAS OU ESQUIZOGRAFIAS DA FUNDAÇÃO CASA
}

\author{
Alessandra Melo ${ }^{1}$
}

Neste texto trazemos uma escrita "como um convite para ir além, para sair, um convite para abandonar o relato repetido" (SKLIAR, 2016, p. 15). Durante dois anos e meio como professora de filosofia me encontrei com os meninos internos em cumprimento de medidas socioeducativas na Fundação CASA, na cidade de Campinas, SP, Brasil. Este fato foi disparador da pesquisa de mestrado: "'Di menor': filosofia da diferença, dobras, imagens e passagens entre vozes marginais da cidade e da Fundação CASA" realizada na Faculdade de Educação da Unicamp.

Aqui de forma experimental compomos com as forças e damos passagem a ecos, vozes e linhas de fuga deste local de reclusão que é a Fundação CASA. Na instituição busca-se a produção de uma ordem que normatiza o agir e o pensar dos meninos e que visa uma subjetividade fácil de controlar, diminuindo-se as singularidades e as diferenças. Apaga-se a individualidade para agregá-los a um bando de menores.

Kafka e as análises feitas por Deleuze e Guattari em sua da obra “ Kafka: por uma literatura menor" (DELEUZE \& GUATTARI, 2017) nos ajudam a pensar este bando de meninos em devir e em privação de liberdade. 'Di menor' é um vetor de bando que assim como Josefina, a camundonga, passa "do animal individuado a matilha" (DELEUZE \& GUATTARI, 2017, p. 38). Desenvolvemos este pensamento, pois 'di menor' tendo sua individualidade apagada pela instituição, sendo matilha, sendo bando não possui nome próprio, não é um, mas sim vários. 'Di menor' não tem rosto, não possui nome e devir loucura estoura todos os canos de água, provoca uma inundação e estraçalha fios elétricos em uma rebelião. 'di menor' devir de bando fecha em círculo e arrebenta uma cadeira de plástico na nuca do agente de segurança por este humilhar uma cozinheira. E enquanto isto dobrado em outro me diz: - Senhora, fica tranquila, senta aqui perto. Tá com medo do que Senhora? Aqui a Senhora é visita.

Ter menos de dezoito anos no Brasil e ser infrator, por hora, significa ter sua identidade protegida pela lei, mas também lhe agrega a este bando 'di menor'. Aqui trazemos recortes dos 'di menor', “agenciamentos coletivos de enunciação” (DELEUZE \& GUATTARI, 2017, p. 38) deste bando, suas falas, escritas disparadas pelo encontros dos meninos internos com as imagens do Coletivo Fabulografias ${ }^{2}$ durante a utilização dos postais do coletivo nas aulas de filosofia.

Os postais do Fabulografias circularam entre os meninos durante algumas aulas e na volta, organicamente, trouxeram falas escritas em uma linguagem e caligrafia próprias. Eram muitos cumprimentos e notícias de quem muito moço já está encarcerado e separado da vida aqui fora. Foram inúmeras as tentativas de comunicação dos meninos pelos postais com o mundo exterior, todas elas bloqueadas pelas normas da instituição.

Aqui apresentamos imagens produzidas pelos meninos e editadas por mim em um momento de fabulação. Sobretudo trazemos um experimento, são sonhos, sementes e germes, notícias, vozes e pensamentos. Uma experiência de "fabulação que se dá na relação"

\footnotetext{
${ }^{1}$ Mestra em linguagem, arte e educação pela UNICAMP; especialista em ensino de filosofia pela UFSCar; atua como professora na rede pública do estado de SP, Brasil. E-mail: a041693@ dac.unicamp.br.

${ }^{2}$ O Coletivo Fabulografias sob a orientação da Profa. Dra. Alik Wunder da Faculdade de Educação da Unicamp, realiza oficinas nos mais diversos espaços, tais como: centros culturais, escolas públicas, universidades, bosques dentre tantos outros. Nestes encontros com diversos grupos de cultura popular, estudantes secundaristas e universitários, professores, poetas e tantos outros, o coletivo se articula na produção de fotografias não autorais experimentais movidas pela pergunta disparadora: “Que Áfricas ventam por você? “. Esta pergunta foi respondida por dezenas de pessoas das mais diversas formas: performance, poema, desenho, dança e música e deram origem aos postais nos quais os meninos internos na Fundação Casa escreveram no verso. Disponível em: 〈http://fabulografias.weebly.com/o-coletivo.html〉.
} 
(DELEUZE, 2007, p. 1) com o real e que fala de muitos e dos muitos eus que compõem estes meninos e nos atravessam em contato com eles.

As vozes são: da professora de filosofia que entra em contato com este novo território dentro da Fundação; de uma multidão polimorfa que fala por muitas vozes (a sociedade, a instituição, mestres que nos guiam nesta travessia, a experiência e tantas outras); E do bando 'di menor' que são muitos e que um caleidoscópio de recortes, imagens e palavras atravessa o texto com uma escrita própria nos postais. Nestas escritas notícias da instituição, mensagens de fé e força, abraços e vontade de encontros.

Enquanto isto na gaiola, no plano da experimentação,

em cena única, cercados de barras de ferro uma multidão grita ....

Multidão (grita): - 'di menor' é o terceiro excluído, é não é! Se 'di menor' é inocente ou culpado não importa. Arrepia-se Aristóteles. Quem tá preso quer fugir! Quem tá preso quer fugir!

professora: - Fugir de onde? Da caverna? Mas isto não seria Platão?

Multidão: - Ei! Atenta, atenta a cada movimento! Da gaiola, do boi, da cela, do quarto.... Sei que há um bando sem nome que está trancado. São crianças, eles mesmo já esqueceram, mas são crianças. 'Di menor 'é alcunha de criança no crime, as vozes das ruas o chamam!

'di menor': - Senhora, ô senhora!!!

Multidão: - É com você!

professora: - Eu? Eu achava que era professora!

Multidão: - Professora? Mas quem é que sabe alguma coisa em cadeia de criança? Aqui você é senhora! E não venha com brincos grandes, eles podem virar armas.

\section{Di menor:}

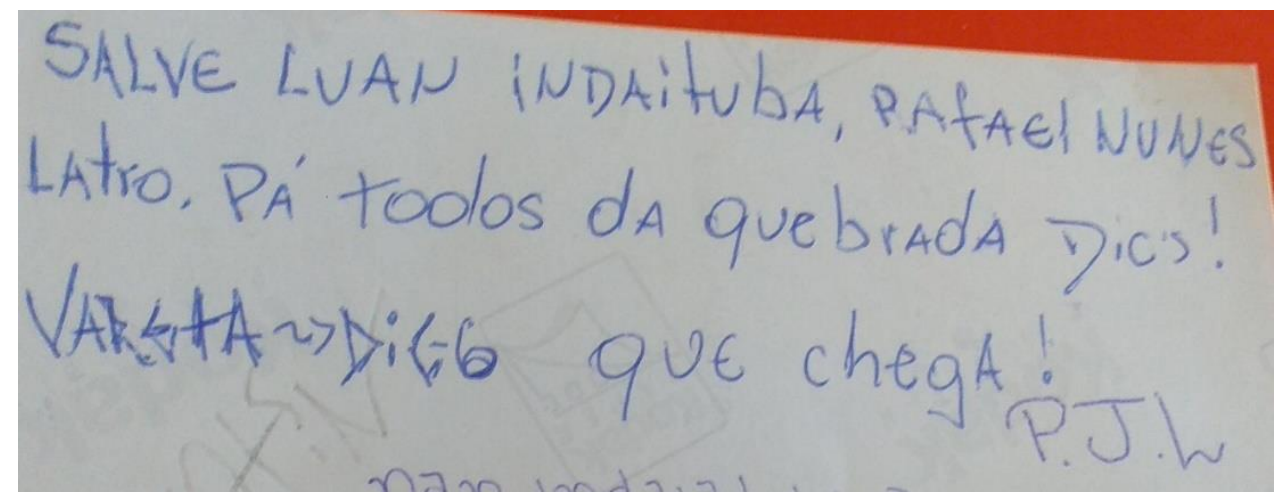


Multidão: - Pelos ecos das paredes conheço os nomes daqueles que já passaram: Ivan, Lequinho, Gigante. Um ontem que dura trezentos anos depois do cativeiro. Paredes de um agora que cisma em tilintar ferrolhos e gatilhos. Intolerável!

'di menor':

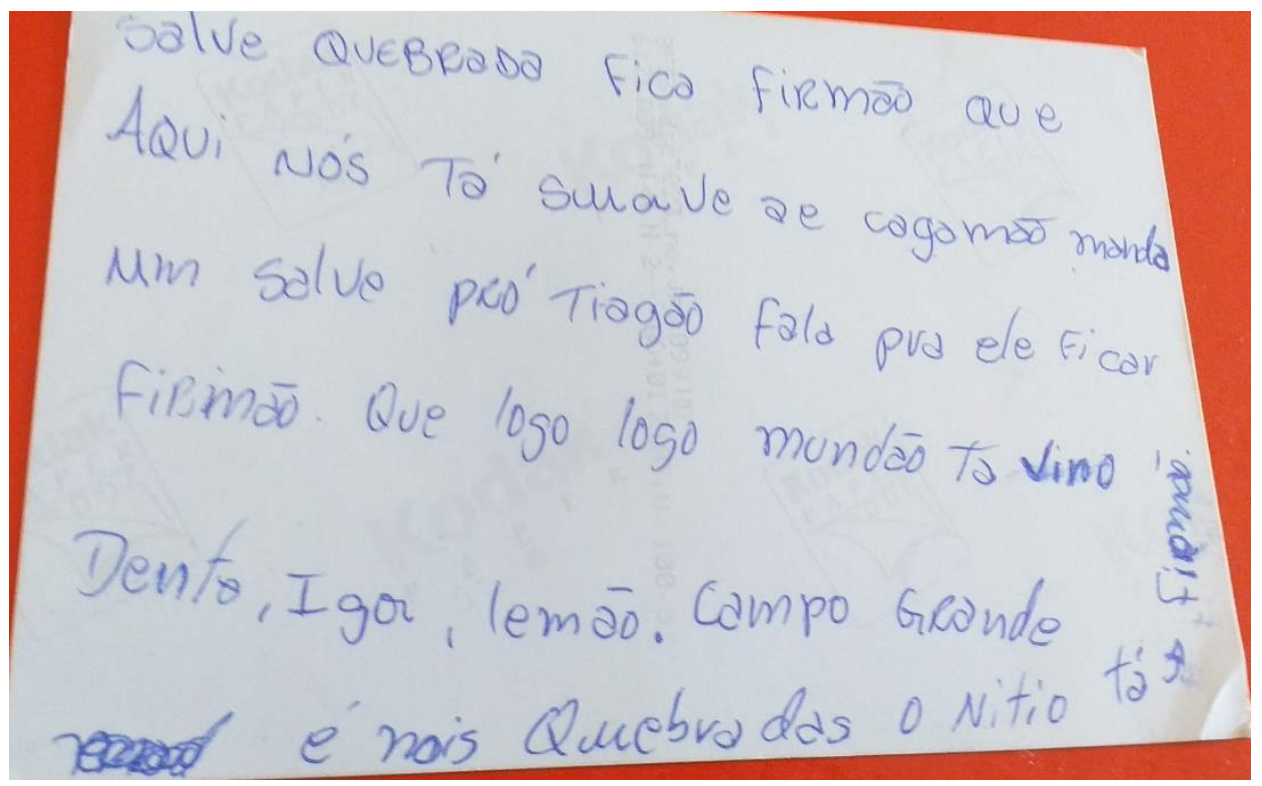

Professora (anotando tudo): - E o último menino quando vem?

Multidão: - O último é nunca, máquina de pobreza e crime que se retroalimenta.

Meninos correm na multidão, meninos como ratos proliferam, meninos que se perdem como Josefina. Que você tanto anota?

Professora: - Linhas de fuga, energia, deslizamentos, resistências. Rupturas e rasuras. É para minha pesquisa de mestrado...

'di menor' (com metade de um dos pés amputado agora gargalha se curvando e interrompe): Senhora, ô senhora! Tem filosofia para crescer o pé?

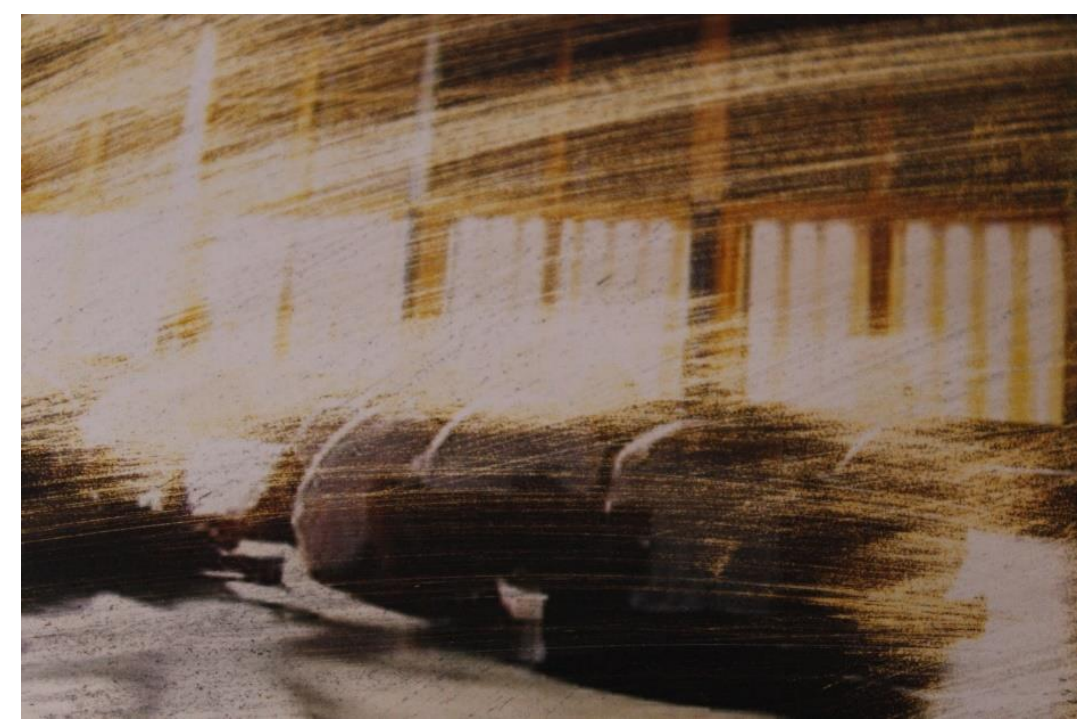


Multidão: - Estes meninos são invisíveis... Eles correm no tempo, matilha sem rosto, sem nome... duvidaram que são invisíveis acredita? Ignoram o tempo. Ouça... o tempo que aqui se arrasta diferente...

\section{Professora: - E como ouvir?}

Multidão: - O tempo aqui é regido pelos fluxos de meninos, são eles que trazem todo tipo de coisa: retenções, larvas, germes. Perceba! Vidas estão por um fio. O hoje arrasta multidões, imagens de passados nunca sonhados, de futuros que nunca existirão, linhas de futuros perdidas em um infinito de impossibilidades. Tilintar de ferrolhos que ressoam no aço daqui (que dizem não ser penitenciária!). Meninos que chegam aos montes dobrados em tantos, moldados como um: cabeça raspada, chinelos azuis, camiseta branca, mãos para trás, máquina de sujeição, silêncio e murmúrio. E não podemos mais nada. Cabe ao poder fazer morrer, mas sobretudo fazer viver, cuidar da espécie, gerir a vida. A rotina dos meninos é cuidadosamente alinhada, já reparou? Refeições, tempo de higiene, tempo de acordar, tempo de dormir.

Professora (perplexa): - Duvidaram que eram invisíveis? Já viu a tarja preta nos olhos daqueles meninos dos jornais? Já viu os apagamentos?

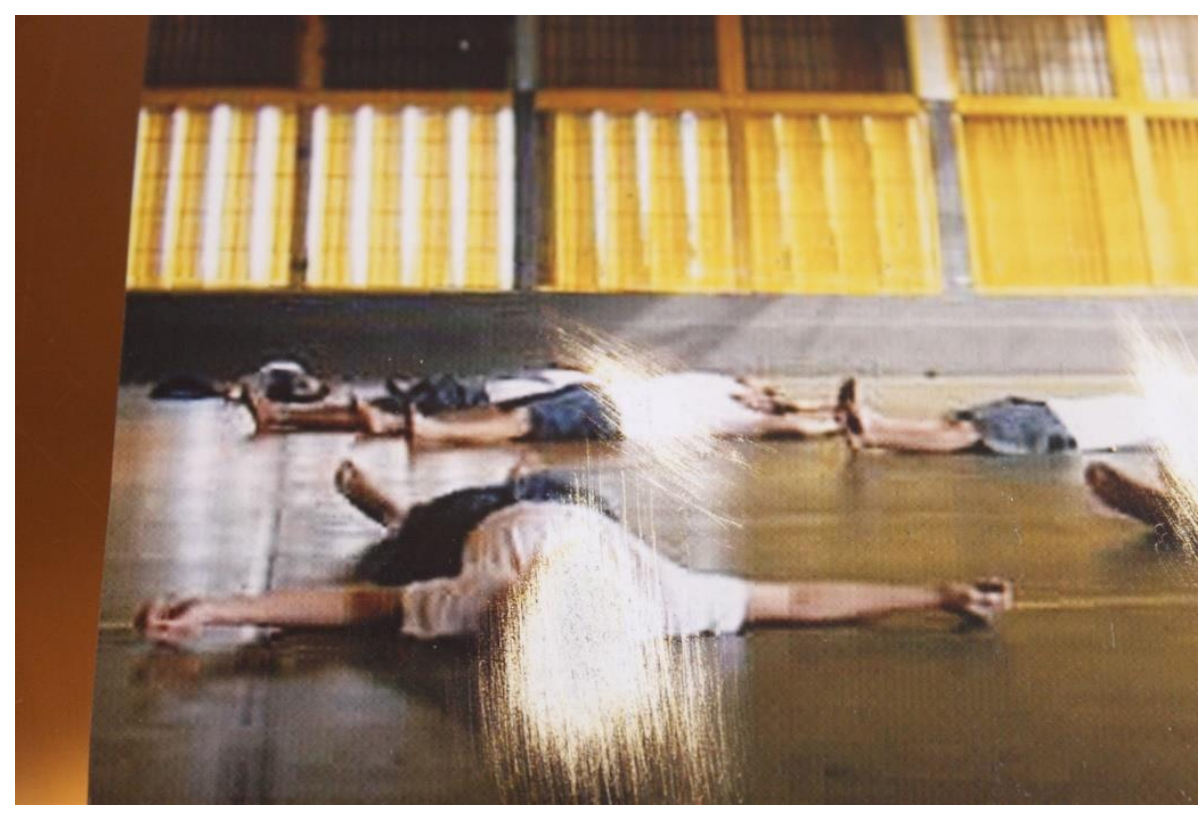

Multidão: - Jornal? As imagens que aqui vemos são um processo de pensamento que se adensa no encontro. Aqui dentro da Fundação Casa como um 'Coletivo invisível' fizemos muito mais, trata-se de "pensar a imagem educação como espaço de experimentação" (WUNDER, 2016 p. 16), como uma aposta de linguagem.

Professora: - A produção de imagens dos meninos traz sempre uma insurreição, uma ruptura, um abalo que compõem uma máquina de guerra contra a homogeneização subjetiva, já notou?

Multidão: -É muito mais que isto, trata-se de uma grande máquina de enunciados que conecta a todos que atravessa. São os embriões de futuro, os processos de criação, os outros mundos, os sons que ainda estão na garganta. Seria isto que nos livra do terror? São meninos, já esqueceram, mas ainda são meninos. Seria essa a insurreição silenciosa? 
Professora: - Eu e minha mania escutadora! Sempre ficando próxima de vidas a perseverar. Notando tempo, deriva, ritmo. Um tempo que transcende a fronteira da arte, não controlável, não passivo. Uma arte escutadora que recorta do real, dos acontecimentos, das imagens, uma arte que demonstra e mostra. Foi isto que fizemos aqui.

Multidão: - Tudo isto é sobre encontros que geram e são narrativas de passagem, protocolos de experimentação, potências que permitem agenciamentos, junções inesperadas, contágio, peste, proliferação. Um novo tipo de verdade que se desvela no processo criativo. Um diagrama instável e fluido... São tantas coisas, mas não se pode dizer só isto... as pessoas esperam uma conclusão sobre esta produção de imagens e palavras na instituição.

Professora: - Conclusão? Nunca foi sobre prisão, sempre foi sobre linhas de fuga e liberdade.

\section{Referências}

BAPTISTELLA, Rosana. Beckett com Deleuze: tecituras possíveis do esgotamento. MáquinaLivro. Máquina-Corpo. Máquina. Estéticas do Esgotamento, 2012 e Cartografias do Esgotamento, 2013.

DELEUZE, Gilles. Conversações, 1972-1990. Trad. Peter Pál Pelbart. Rio de Janeiro, RJ: Editora 34, 1992.

DELEUZE, Gilles. Cinema 2: A imagem-tempo. Trad. Heloísa de Araújo Ribeiro. São Paulo: Brasiliense, 2007.

DELEUZE, Gilles. PARNET, Claude. Diálogos. Tradução Eloisa Araújo Ribeiro. São Paulo: Editora Escuta, 1998.

DELEUZE, Gilles; GUATTARI, Félix. Kafka: Por uma literatura menor. Belo Horizonte: Editora Autêntica, 2017.

DELEUZE, Gilles; GUATTARI, Félix. Mil Platôs: capitalismo e esquizofrenia. v. 5. Trad. Peter Pál Pelbart e Janice Caiafa. São Paulo: Editora 34, 1997 .

DELEUZE, Gilles. Sobre o teatro: O esgotado. Tradução de Ovídio de Abreu e Roberto Machado. Rio de Janeiro: Zahar, 2010

FOUCAULT, Michel. Vigiar e Punir. tradução de Raquel. Ramalhete. Petrópolis: Vozes, 1987.

LAPOUJADE, David. As existências mínimas. São Paulo: Editora N2, 2017

LINS, Daniel. A Escrita Rizomática. Revista Polichinello, n. 10, Palmas, 2012.

RANCIÉRE, Jacques. O mestre ignorante. São Paulo: Autêntica, 2014

SKLIAR, Carlos. Escrevendo e lendo sobre a identidade, a diferença e a solidão. Leitura Teoria \& Prática, Campinas, ALB, 2016. 
WUNDER, Alik. Uma educação visual por entre a literatura, fotografia e filosofia. Políticas Educativas, Porto Alegre, 2009.

WUNDER, Alik. Sensações inauditas mundos possíveis? Revista Observatório, Palmas, 2016. 